International Journal of Clinical Dermatology \& Research (IJCDR)

ISSN 2332-2977

\title{
Acral Melanoma: Experience of Dermatology Department, Hassan II University Hospital of Fez in Morocco
}

Case Series

Hadj I, Meziane M, Gallouj S, Mernissi FZ

Dermatology department, Hassan II Univerity Hospital, Fez, Morocco.

\begin{abstract}
Acral melanoma represents 3 to 13\% of all cutaneous melanoma in Caucasians. In Morocco, this location is predominant. Throught our study, we intend to describe the epidemiological, clinical, pathological, and prognosis of acral melanoma cases listed in dermatology department of Hassan II University Hospital of Fez in Morocco, in the period from January 2009 and April 2014.
\end{abstract}

Key words: Acral Melanoma; Amelanotic Melanoma; Trauma.

\section{*Corresponding Author:}

Hadj I,

Dermatology department, Hassan II Univerity Hospital, Fez, Morocco. E-mail: iman.hadj@gmail.com

Received: June 11, 2014

Accepted: July 05, 2014

Published: July 09, 2014

Citation: Hadj I, Meziane M, Gallouj S, Mernissi FZ(2014) Acral Melanoma: Experience of Dermatology Department, Hassan II University Hospital of Fez in Morocco. Int J Clin Dermatol Res. 2(4), 25-26, doi: http://dx.doi.org/10.19070/2332-2977-140007

Copyright: Hadj I (C) 2014. This is an open-access article distributed under the terms of the Creative Commons Attribution License, which permits unrestricted use, distribution and reproduction in any medium, provided the original author and source are credited.

\section{Introduction}

Acral melanoma is a very rare variety of cutaneous melanoma, it' is defined as a melanoma located on the non-hair-bearing skin of the palms and soles or under the nails [1]. amelanotic malignant melanoma is sometimes misdiagnosed. The prognosis of this tumor remains reserved. We report the epidemiological, clinical, dermoscopic, histopathological features, prognosis and evolving of our population.

\section{Materials and Methods}

All cases of acral melanoma were identified retrospectively between January 2009 and April 2014. For each patient, epidemiological information (age, gender, medical history, sun exposure, previous trauma, disease duration before diagnosis), clinical, dermoscopic, histological, therapeutic and outcome were recorded.

\section{Results}

We compiled 54 cases of melanoma during the study period, 31 patients had an acral location, which represents $57 \%$ of all melanomas. The male to female ratio was $1 / 1.2$, with a mean age at the time of diagnosis of $61(32-86) .80 \%$ of patients were fitzpatrick's skin type IV, without history of excessive sun exposure. Only 8 patients $(25 \%)$ reported previous trauma. The notion of manipulation was reported in 11 cases (35\% of patients). The most common site was the foot $(87 \%)$, with one case of melano$\mathrm{ma}$ of the thumb and another of the index. The pigmented form $(77,4 \%)$ and the exophytic one $(35 \%)$ were predominant. The size varied from 0.5 to $12 \mathrm{~cm}$. The average time to diagnosis was 30 months (3 months-10 years). The most common dermoscopic features were: parallel ridge pattern, irregular diffuse pigmentation, polymorphous vessels, blue-white veil. The Breslow thikness was $>4 \mathrm{~mm}$ in $35.4 \%$ of cases and the most common histological type was the acral lentiginous melanoma (38.7\%). Metastases were found at diagnosis in $55 \%$ of patients, dominated by the lung $(67.7 \%)$ the lymph node (47.7\%),bone and liver (13\%), and at last brain and adrenal metastases $(6.54 \%) .45 \%$ of patients were classified as stage IV. The search for C-Kit mutation and sentinel lymph node were not performed in any of our patients. Different treatments were given to patients depending on stage. Five patients died after an average time of 9,3 months, 12 patients were lost of the follow immediately, and 12 patients after a mean follow up of 6 months.

\section{Discussion}

Melanoma is an aggressive malignancy whose incidence has increased in worldwide in white populations, especially where fairskinned peoples receive excessive sun exposure over the last 20 years. The acral melanoma is a rare variety which represents only $2-13 \%$ of all melanomas in Caucasians [2], however, this location is predominant in North Africa (more than $50 \%$ of melanomas in Tunisia [3] and Algeria [4]) and sub-Saharan Africa; according to the study of Pitche et al [5]; 63, 5\% of melanomas Togo are localized on the feet and $19 \%$ of the hands, these results are similar to the figure of $57 \%$ found in our series, this location is also common in Asians (35-49\%), Hispanic (20-34\%) and African Americans (50-70\%) $[1,2,6,7]$.

The acral melanoma, like other subtypes of melanoma is predominant in female patients in caucasians, the male/female ration is $1 / 1.6$ [8]. However, this figure is a trend to be reversed in our country with a male / female ratio of 1.2 in our series, this result is also similar to those recorded in Tunisia (1.19) [3] and Togo 
(1.03) [5]. In Asian male predominance is much sharper, with a sex ratio that exceeds 2 for all melanomas or 6 for acral melanoma $[9,10]$. The average age of our patients was 61 years, which joins the data in the literature [8].

The acral melanoma occurs most often like a black or brown macule with irregular edge, nodules, or exophytic tumors; in our series, this last form was predominant, because probably of the diagnostic delay and self manipulation; which also may participate in tumor dissemination ( $45 \%$ of patients were classified stage IV (according to the sixth edition of the pTNM classification of the International Union Against Cancer (UICC) and the American Joint Comittee on Cancer (AJCC)) and increased Breslow thickness ( $>4 \mathrm{~mm}$ in $35.4 \%$ in our series). Amelanotic malignant melanoma variety was found in $20 \%$ of our patients; this form may mimic other entities such as pyogenic granuloma, poorly plantar wart or wound [11], which can participate in the diagnostic delay. The predominant histological type is the acral lentiginous melanoma which joined the literature data $[3,8]$.

Unlike other types of melanoma, sun exposure does not appear to play a role in acral melanoma, the concept of trauma, long disputed, is currently controversial; in the retrospective study of Kaskel [12], only 8,7\% (32 patients) of the patients considered an association of trauma and melanoma formation likely, of these 32 patients, 22 patients reported a single event, and 10 patients a persisting irritation. He concluded, that based on epidemiological, clinical and scientific research to date, there seems to be no evidence of the role of trauma in the pathogenesis of formation of melanoma.

Briggs [13] says that, if trauma as a common event at acral sites is a cofactor for melanoma, then the incidence of subungual and other acrolentiginous melanomas should consequently be higher. Several authors have pointed to the possibility that previous injuries were coincidences recalled to the memory of the patients during the subsequent appearance of a tumor (recall bias) and that secondary trauma have played a revealing role in attracting the attention of the patient or physician to a preexisting lesion. Moreover, this notion of trauma was found in 8 cases in our series. [11].

Acral melanomas have a low incidence of BRAF mutations but are more likely to harbor mutations of KIT. KIT (CD117) encodes a tyrosine kinase receptor for the stem cell factor and plays a key role in melanocytic development, migration, and proliferation. It is the target of several small molecule inhibitors such as imatinib and sunitinib, which are already used in the clinic and have significantly improved survival in gastrointestinal stromal tumor (GIST) patients with activating KIT mutations. A recently published study showed that imatinib significantly prolongs the lifespan of patients with metastatic melanoma harboring KIT mutations [1].

C-KIT mutation is detected in approximately $23 \%$ to $36 \%[14,15]$ acral melanoma in Caucasians, it is less common among Asians, in the study of Si et al [16] it is present in $11.9 \%$ of acral melanomas.

It is always important to consider the C-KIT mutational status of acral melanoma in each ethnic group, to predict the effectiveness of targeted therapies [17].

In our patients were given different treatments depending on the stage, the search for C-Kit mutation was not performed in any case, do not allow the use of targeted therapies.

\section{Conclusion}

The acral melanoma is a very aggressive tumor whose incidence is increasing; a good knowledge of these clinical presentations, an adequate care, as well as specific preventive messages to our population may guarantee a better prognosis.

\section{References}

[1]. Dai B, Cai X, Kong YY, Yang F, Shen XX, et al.(2013)Analysis of KIT expression and gene mutation in human acral melanoma: with a comparison between primary tumors and corresponding metastases/recurrences. Hum Pathol Aug; 44(8), 1472-8.

[2]. Stalkup JR, Orengo IF, Katta R (2002) Controversies in acral lentiginous melanoma.Dermatol Surg Nov; 28(11):1051-9.

[3]. El Euch D, Zaraa I, Driss M, Fourati M, Mokni M, et al. (2010) Le melanoma en Tunisie: étude anatomoclinique de 46 cas. Ann Dermatol Vénéréol;137: 391-2.

[4]. Boudghene-Stambouli O, Merad-Boudia A (1997) Le mélanome au Maghreb. Ann Dermatol Venereol;124:559.

[5]. Pitché P,Napo-Koura G ,Tchangai-Walla K (2005) Epidemiology of melanoma in Togo. Int J Dermatol;44( Suppl 1), 44-5.

[6]. Hutcheson AC, Mc Gowan IV JW, Maize Jr JC, Cook J (2007) Multiple primary acral melanomas in African- Americans: a case series and review of the literature. Dermatol surg Jan;33(1):1-10

[7]. Shoo BA, Kashani-Sabet M (2009) Melanoma arising in African-, Asian-, Latino andNative-American populations. Semin Cutan Med Surg; 28:96102.

[8]. Kuchelmeister C, Schaumburg-Lever G, Garbe C (2000) Acral cutaneous melanoma in caucasians: clinical features, histopathology and prognosis in 112 patients. Br J Dermatol; 143: 2756-280.

[9]. Lin CS, Wang WJ, Wong CK (1990) Acral melanoma. A clinicopathologic study of 28 patients.Int J dermatol Mar; 29(2):107-12.

[10]. Fortin PT, Freiberg AA, Rees R, Sondak VK, Johnson TM (1995) Malignant melanoma of the foot and ankle.J Bone Joint Surg Am;77:1396-403.

[11]. Lesage C, Journet-Tollhupp J, Bernard P,Grange F (2012) Mélanome acral post-traumatique : une réalité sous-estimée ?. Ann Dermatol Vénéréol;139 : $727-31$.

[12]. Kaskel P, Kind P, Sander S, Peter RU, Krahn G (2000) Trauma and melanoma formation: a true association. Br J Dermatol; 143:749-53.

[13]. Briggs JC (1984) The role of trauma in the aetiology of malignant melanoma: a review article. Br J Plast Surg;37:514-6.

[14]. Curtin JA, Busam K, Pinkel D, Bastian BC (2006) Somatic activation of KIT in distinct subtypes of melanoma.J Clin Oncol Sep 10;24(26):4340-6.

[15]. Beadling C, Jacobson-Dunlop E, Hodi FS, Le C, Warrick A, et al.(2008) KIT gene mutations and copy number in melanoma subtypes.Clin Cancer Res Nov 1;14(21):6821-8.

[16]. Si L, Guo J (2013) C-kit-mutated melanomas: the Chinese experience. Curr Opin Oncol . Mar; 25(2):160-5.

[17]. Ashman LK, Griffith R (2013) Therapeutic targeting of C-KIT in cancer. Expert Opin Investig Drugs. Jan;22(1);103-15. 